\title{
Iron-Catalysed Aerobic Oxidative C-C Bond Cleavage of Ketones for the Synthesis of Primary Amides
}

\author{
Haosheng Zhan ${ }^{a}$ \\ Zhiwei Hua \\ Weihua Tao ${ }^{a}$ \\ Min Ling \\ Wei Cao \\ Jing Lin ${ }^{a}$ \\ Zhenhua Liub \\ Yu Wang*a \\ Zhongxue Fang*a (D) \\ a School of Chemistry and Environmental Engineering, Yancheng \\ Teachers University, Yancheng 224007, P. R. of China \\ fangzhongxue120@163.com \\ ${ }^{b}$ College of Chemistry, Chemical Engineering and Materials Sci- \\ ence, Shandong Normal University, Jinan 250014, P. R. of China
}

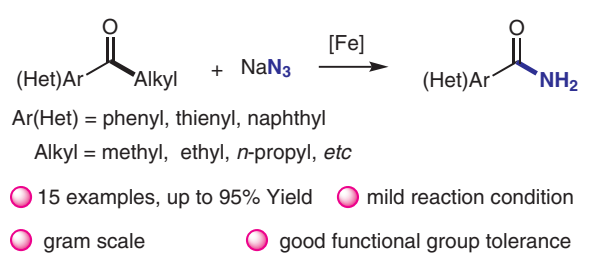

gram scale good functional group tolerance

\author{
Received: 01.01.2019 \\ Accepted after revision: 28.01.2019 \\ Published online: 18.02 .2019 \\ DOI: 10.1055/s-0037-1611676; Art ID: so-2019-d0001- \\ License terms: (c)
}

Abstract An iron-catalysed aerobic oxidative C-C bond cleavage of ketones for the synthesis of primary amides has been developed using TEMPO and oxygen as an oxidant. This reaction tolerates a wide range of substrates, and primary amides are obtained in good to excellent yields. Substrates with long-chain alkyl substituents could also be selectively cleaved and converted into the corresponding amides.

Key words C-C bond cleavage, ketone, primary amide, amide, ironcatalysis

Aromatic primary amides have been utilised extensively in organic synthesis, chemical engineering and pharmaceutical chemistry. ${ }^{1}$ They are also present in biologically active molecules. ${ }^{2}$ In organic synthesis, primary amides can be readily converted into amines, nitriles and heterocycles. For these reasons, numerous synthetic methodologies have been developed for their preparation. Typical examples are the ammonolysis of carboxylic acids, ${ }^{3}$ rearrangement of benzaldoximes, ${ }^{4}$ palladium-catalysed carbonylation of organohalides with ammonia, ${ }^{5}$ direct oxidation of benzylamines $^{6}$ or benzyl alcohol ${ }^{7}$ to the corresponding benzamides, and hydration of the corresponding nitriles. ${ }^{8}$ In addition, use of iodine as catalyst could also lead to $\mathrm{C}-\mathrm{N}$ bond formation via $\mathrm{C}-\mathrm{C}$ bond cleavage to construct amides. ${ }^{9}$

Recently, transition-metal-catalysed $\mathrm{C}-\mathrm{C}$ bond cleavage methods have been developed as a powerful tool to construct $\mathrm{C}-\mathrm{N}$ bonds. For instance, Song and co-workers presented a $\mathrm{Cu}_{2} \mathrm{O}$-catalysed aerobic oxidative decarboxylative ammoxidation of phenylacetic acids or $\alpha$-hydroxy-phenylacetic acids to primary benzamides. ${ }^{10}$ Recently, Sun applied aerobic oxidative $\mathrm{C}-\mathrm{CN}$ bond cleavage of benzyl cyanide over a copper catalyst to the synthesis of primary amides. ${ }^{11}$ Zhou discovered a method for $N$-benzoylation of amines via selective aerobic $\mathrm{C}-\mathrm{C}$ bond cleavage of 1,2-diarylethan-1ones over a copper catalyst. ${ }^{12}$ In particular, Jiao and coworkers reported the aerobic oxidative $\mathrm{C}-\mathrm{C}$ bond cleavage of unstrained ketones to form amides, catalysed by a copper catalyst. ${ }^{13}$ By using this protocol, Huang's group described the transformation of ketones into amides via $\mathrm{C}(\mathrm{CO})-\mathrm{C}(\mathrm{al}-$ $\mathrm{kyl}$ ) bond cleavage directed by picolinamide using the same catalyst. ${ }^{14}$ It is noteworthy that, in most of these methods, a stoichiometric or excess amount of oxidant, additives, or special preparation of the substrates may be required for a successful outcome. Therefore, the development of an efficient catalytic system towards aerobic oxidative unstrained $\mathrm{C}-\mathrm{C}$ bond cleavage is desirable. As part of our continued interest in $\mathrm{C}-\mathrm{C}$ bond-cleavage reactions, ${ }^{15}$ we herein report an iron-catalysed aerobic oxidative $\mathrm{C}-\mathrm{C}$ bond cleavage of ketones for the synthesis of primary amides (Scheme 1).

Our initial efforts commenced with 4-methoxyacetophenone (1a) and sodium azide as the model substrates in the presence of $\mathrm{FeCl}_{3}, 2,2,6,6$-tetramethylpiperidine- $\mathrm{N}$ oxyl (TEMPO) in aqueous DMSO at $120^{\circ} \mathrm{C}$ for $30 \mathrm{~h}$ under an oxygen atmosphere and the desired 4-methoxybenzamide (2a) was isolated in 75\% yield (Table 1, entry 1 ). Encouraged by this result, we continued to optimise the reaction conditions. To find the best catalysts, $\mathrm{Fe}\left(\mathrm{NO}_{3}\right)_{3}, \mathrm{Fe}_{2}\left(\mathrm{SO}_{4}\right)_{3}$, ferrocene, $\mathrm{Fe}(\mathrm{acac})_{3}, \mathrm{Fe}_{2} \mathrm{O}_{3}$ and $\mathrm{Fe}$ were examined. The use of $\mathrm{Fe}\left(\mathrm{NO}_{3}\right)_{3}$ and $\mathrm{FeCl}_{2}$ showed lower efficiency, while ferrocene, $\mathrm{Fe}(\mathrm{acac})_{3}, \mathrm{Fe}_{2} \mathrm{O}_{3}$ and $\mathrm{Fe}$ gave moderate yields (entries 


\section{Srapen}

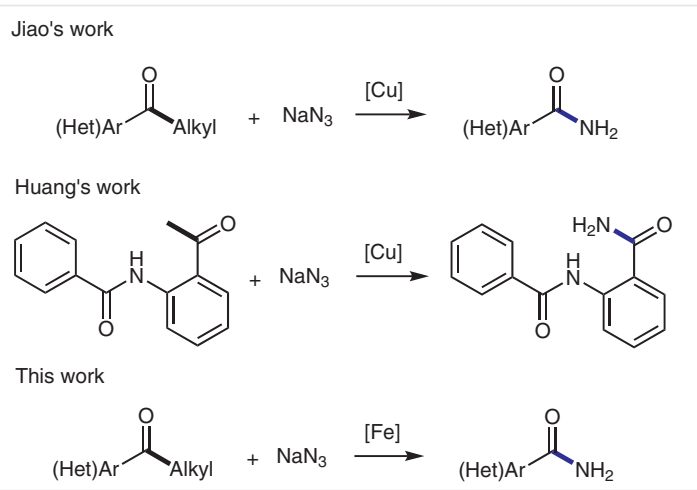

Scheme 1 Reported transition-metal-catalysed protocols for C-C bond cleavage of ketones for the synthesis of primary amides

2-8). $\mathrm{Fe}_{2}\left(\mathrm{SO}_{4}\right)_{3}$ turned out to be the most effective catalyst, affording a yield of 95\% (entry 9). Investigation of oxidants showed that tert-butyl hydroperoxide (TBHP), dibenzoyl peroxide (BPO), PhI(OAc) , 2-iodoxybenzoic acid (IBX), $\mathrm{H}_{2} \mathrm{O}_{2}, \mathrm{~K}_{2} \mathrm{~S}_{2} \mathrm{O}_{8}$ and $\left(\mathrm{NH}_{4}\right)_{2} \mathrm{~S}_{2} \mathrm{O}_{8}$ resulted in no reaction (entries 10-15). The reaction rate slowed down, and low yields were obtained when $N$-methyl pyrrolidone (NMP), 1,2,3-trichloropropane (TCP) or mesitylene were used as reaction solvent (entries 16-18).

Table 1 Optimisation of the Reaction Conditions ${ }^{\mathrm{a}}$

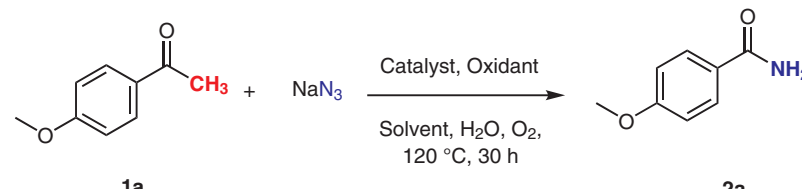

1a

$2 a$

\begin{tabular}{|c|c|c|c|c|}
\hline Entry & Catalyst & Oxidants & Solvent & Yield (\%) \\
\hline 1 & $\mathrm{FeCl}_{3}$ & TEMPO & DMSO & 75 \\
\hline 2 & $\mathrm{Fe}\left(\mathrm{NO}_{3}\right)_{3}$ & TEMPO & DMSO & 38 \\
\hline 3 & $\mathrm{FeCl}_{2}$ & TEMPO & DMSO & 40 \\
\hline 4 & Ferrocene & TEMPO & DMSO & 67 \\
\hline 5 & $\mathrm{Fe}(\mathrm{acac})_{3}$ & TEMPO & DMSO & 52 \\
\hline 6 & $\mathrm{Fe}_{2} \mathrm{O}_{3}$ & TEMPO & DMSO & 60 \\
\hline 7 & $\mathrm{Fe}_{3} \mathrm{O}_{4}$ & TEMPO & DMSO & 62 \\
\hline 8 & $\mathrm{Fe}$ & TEMPO & DMSO & 73 \\
\hline 9 & $\mathrm{Fe}_{2}\left(\mathrm{SO}_{4}\right)_{3}$ & TEMPO & DMSO & 95 \\
\hline 10 & $\mathrm{Fe}_{2}\left(\mathrm{SO}_{4}\right)_{3}$ & $\mathrm{TBHP}^{\mathrm{C}}$ & DMSO & 0 \\
\hline 11 & $\mathrm{Fe}_{2}\left(\mathrm{SO}_{4}\right)_{3}$ & $\mathrm{Phl}(\mathrm{OAc})_{2}{ }^{\mathrm{c}}$ & DMSO & 0 \\
\hline 12 & $\mathrm{Fe}_{2}\left(\mathrm{SO}_{4}\right)_{3}$ & $\mathrm{IBX}$ & DMSO & 0 \\
\hline 13 & $\mathrm{Fe}_{2}\left(\mathrm{SO}_{4}\right)_{3}$ & $\mathrm{H}_{2} \mathrm{O}_{2}{ }^{\mathrm{c}}$ & DMSO & 0 \\
\hline 14 & $\mathrm{Fe}_{2}\left(\mathrm{SO}_{4}\right)_{3}$ & $\mathrm{~K}_{2} \mathrm{~S}_{2} \mathrm{O}_{4}{ }^{\mathrm{c}}$ & DMSO & 0 \\
\hline 15 & $\mathrm{Fe}_{2}\left(\mathrm{SO}_{4}\right)_{3}$ & $\left(\mathrm{NH}_{4}\right)_{2} \mathrm{~S}_{2} \mathrm{O}_{8}{ }^{\mathrm{C}}$ & DMSO & 0 \\
\hline 16 & $\mathrm{Fe}_{2}\left(\mathrm{SO}_{4}\right)_{3}$ & TEMPO & NMP & 25 \\
\hline 17 & $\mathrm{Fe}_{2}\left(\mathrm{SO}_{4}\right)_{3}$ & TEMPO & TCP & 16 \\
\hline
\end{tabular}

Table 1 (continued)

\begin{tabular}{|c|c|c|c|c|}
\hline Entry & Catalyst & Oxidants & Solvent & Yield (\%) \\
\hline 18 & $\mathrm{Fe}_{2}\left(\mathrm{SO}_{4}\right)_{3}$ & TEMPO & Mesitylene & 11 \\
\hline $19^{d}$ & $\mathrm{Fe}_{2}\left(\mathrm{SO}_{4}\right)_{3}$ & TEMPO & DMF & 5 \\
\hline 20 & - & TEMPO & DMSO & 0 \\
\hline 21 & $\mathrm{Fe}_{2}\left(\mathrm{SO}_{4}\right)_{3}$ & - & DMSO & 0 \\
\hline \multicolumn{5}{|c|}{$\begin{array}{l}\text { a Reagents and conditions: } \\
\text { mmol), TEMPO (0.08 mol) } \\
\mathrm{O}_{2} \text { atmosphere for } 30 \mathrm{~h} \text {. } \\
\text { b Isolated yield. } \\
{ }^{c} \text { Oxidant ( } 120 \text { mol\%). } \\
{ }^{d} \mathrm{H}_{2} \mathrm{O} \text { ( } 0 \text { equiv). }\end{array}$} \\
\hline
\end{tabular}

Decreasing the amount of water led only to trace amounts of product (Table 1 , entry 19 ). No reaction occurred in the absence of either an iron catalyst or TEMPO (entries 20 and 21), indicating that the combination of $\mathrm{Fe}_{2}\left(\mathrm{SO}_{4}\right)_{3}$ and TEMPO plays an important role in the formation of primary amides.

The scope of this iron-catalysed $\mathrm{C}-\mathrm{C}$ bond-cleavage reaction was then examined in detail under the optimised reaction conditions (Table 2). Firstly, 4-methoxyacetophenone (1a) reacted smoothly to yield 4-methoxybenzamide (2a) in 95\% yield. Acetophenone derivatives with alkyl substituents in the para-position performed well, giving the desired products in moderate to excellent yields ( $\mathbf{2 b - f}$ ). Notably, acetophenone derivatives bearing bulky cyclohexyl or phenyl substituents in the para-position were well tolerated, affording the desired products $\mathbf{2} \mathbf{g}$ and $\mathbf{2 h}$ in moderate to excellent yields. Acetophenone (1i) reacted smoothly to give benzamide ( $\mathbf{2 i}$ ) in $66 \%$ yield. In addition, this transformation could also tolerate aryl ketones with electron-withdrawing substituents on the aryl ring; for example, 4-chlorobenzamide $(\mathbf{2 j}$ ) was obtained in $70 \%$ yield. When 3,4 -dimethylacetophenone was used, the corresponding 3,4dimethylbenzamide 2k was obtained in $85 \%$ yield. Moderate yields were obtained for $\mathbf{2 1 - 0}$, when the same reaction conditions were applied to heterocyclic aryl compound and acetylnaphthalene $\mathbf{1 1}$ and 1o, respectively. Acetophenones ortho-substituted with a methyl group or fluorine substituent gave only trace amounts of product under the optimal conditions (Scheme S1), and acetophenones with strongly electron-withdrawing substituents, such as $\mathrm{NO}_{2}-$ or $\mathrm{CF}_{3}-$, at the para-position did not give the target products under these conditions (Scheme S2). These results indicate that steric and electronic effects have a great influence on the efficiency of the conversion.

With the substrate scope for this transformation established, we explored further substrates under the standard conditions (Table 3). To our satisfaction, various aryl alkyl ketones reacted successfully, and the corresponding arylamides were obtained in good yields. Chemoselective cleavage of the $C(\mathrm{CO})-C($ alkyl) bond was always the case using this method. Aryl substituents bearing electron-donating 
Table 2 Iron-Catalysed Aerobic Oxidative C-C Bond Cleavage of Ketones for the Synthesis of Primary Amides ${ }^{\mathrm{a}}$

(2)

a Reaction conditions: 1 (0.4 mmol), $\mathrm{NaN}_{3}(1.2 \mathrm{mmol}), \mathrm{Fe}_{2}\left(\mathrm{SO}_{4}\right)_{3}(0.04$ $\mathrm{mmol})$, TEMPO (0.08 mol), $\mathrm{H}_{2} \mathrm{O}(12 \mathrm{mmol}), \mathrm{DMSO}(2 \mathrm{~mL})$, at $120^{\circ} \mathrm{C}$ under $\mathrm{O}_{2}$ atmosphere for $30 \mathrm{~h}$.

Isolated yield. groups such as a methyl or a methoxy group were also tolerated by this catalytic system (entries 1 and 2). A longchain alkyl substituent could be selectively cleaved and converted into the corresponding amide $\mathbf{2} \mathbf{i}$ (entries 3 and 4). 1-Benzoylacetone also furnished $\mathbf{2 i}$ in $86 \%$ yield (entry 5). Such aryl alkyl ketones were inactive under the conditions of the aldehyde syntheses described by Bi's group. ${ }^{16}$ This indicates that our conversion might proceed through a different reaction route.

Table 3 Scope of the Reaction with Respect to Long-Chain Alkyl Ketones $^{\mathrm{a}}$

Entry
5<smiles>CC(=O)CC(=O)c1ccccc1</smiles>
$2 \mathrm{i}$ 86
Reaction conditions: 1 (0.4 mmol), $\mathrm{NaN}_{3}(1.2 \mathrm{mmol}), \mathrm{Fe}_{2}\left(\mathrm{SO}_{4}\right)_{3}(0.04$ $\mathrm{mmol})$, TEMPO $(0.08 \mathrm{~mol}), \mathrm{H}_{2} \mathrm{O}(12 \mathrm{mmol}), \mathrm{DMSO}(2 \mathrm{~mL})$, at $120^{\circ} \mathrm{C}$ under $\mathrm{O}_{2}$ atmosphere for $30 \mathrm{~h}$.

${ }^{b}$ Isolated yield.

To investigate the reaction mechanism of the $\mathrm{C}-\mathrm{C}$ bond cleavage of ketones for the synthesis of primary amides, some possible intermediates were prepared and used under the standard conditions (Scheme 2). However, 4-methoxybenzaldehyde, 2-hydroxy-1-(4-methoxyphenyl)ethan-1one, 2-(4-methoxyphen yl)-2-oxoacetaldehyde and 2-(4methoxyphenyl)-2-oxoacetic acid did not lead to formation of 4- methoxybenzamide (2a) under the standard reaction conditions (Scheme 2, a-d). These control experiments indicate that the ketone substrate may react first with the azide nucleophile and then undergo the oxidation process catalysed by the $\mathrm{Fe} / \mathrm{O}_{2}$ system.

On the basis of the above results and the published reports, ${ }^{11-14,17}$ a plausible mechanism for this iron-catalysed $\mathrm{C}-\mathrm{C}$ bond cleavage of aryl alkyl ketones leading to primary amides can be proposed (Scheme 3 ). The starting material 1 is initially attacked by the azide nucleophile to obtain labile intermediate $\mathbf{I}$ in a potentially reversible process. Subsequent aerobic oxidation of intermediate I generates a hydroxylated intermediate $\mathbf{I I} .^{18}$ The latter intermediate II 
(a)

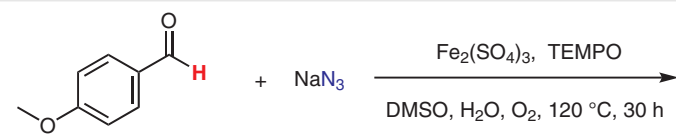

(b)

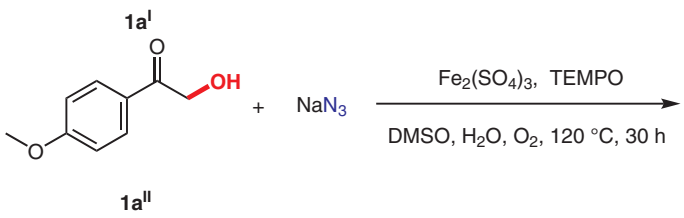

(c)

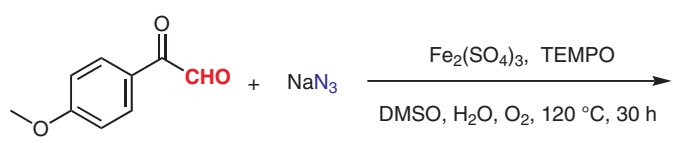

(d)

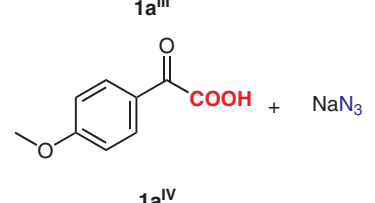<smiles>COc1ccc(C(N)=O)cc1</smiles><smiles>COc1ccc(C(N)=O)cc1</smiles>

2a, trace<smiles>COc1ccc(C(N)=O)cc1</smiles>

2a, $0 \%$<smiles>COc1ccc(C(N)=O)cc1</smiles>

2a, $0 \%$

Scheme 2 Control experiments

can then undergo proton transfer to provide intermediate III, which can fragment to produce intermediate IV through $\mathrm{C}-\mathrm{C}$ bond cleavage with release of molecular nitrogen and an aldehyde as the by-products. ${ }^{19}$ In some cases, activated aldehydes can undergo a further Schmidt reaction to produce the corresponding nitriles. Finally, tautomerism of IV affords the desired amide 2 .

$$
\underset{\mathrm{H}_{2} \mathrm{C}}{\rightleftharpoons}
$$

Scheme 3 Plausible reaction mechanism

To demonstrate the ease of this protocol, we conducted a scale-up experiment to establish its synthetic utility (Scheme 4). Thus, a gram-scale reaction of $\mathbf{1 a}$ with $\mathrm{NaN}_{3}$ in the presence of $\mathrm{Fe}_{2}\left(\mathrm{SO}_{4}\right)_{2}$ (10 mol\%), TEMPO (20 mol\%) and $\mathrm{H}_{2} \mathrm{O}(300 \mathrm{mmol}$ ) was carried out, giving the desired product 3a in $94 \%$ isolated yield.

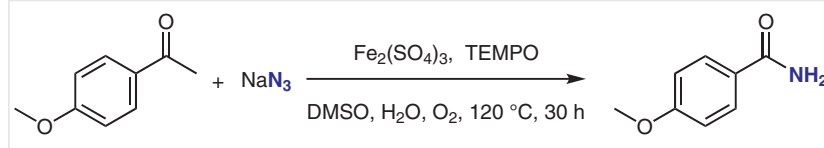

1a, $10 \mathrm{mmol} \quad 30 \mathrm{mmol}$

2a, $94 \%$

Scheme 4 Gram-scale reaction

In summary, we have developed a novel iron-catalysed aerobic oxidative $\mathrm{C}-\mathrm{C}$ bond cleavage of ketones. ${ }^{20}$ This protocol provides a simple and green approach for the preparation of primary amides. In this amination, a variety of substituted acetophenone derivatives as well as more challenging aryl ketones with long-chain alkyl substituents were well-tolerated. The present method is practical and economical, and the starting materials are readily available. As a synthetically practical method, a gram-scale synthesis has also been demonstrated.

\section{Funding Information}

The authors wish to thank the National Natural Science Foundation of China (21506017), The Natural Science Foundation of the Jiangsu Higher Education Institutions of China (18KJB610021) and the Flagship Major Development of Jiangsu Higher Education Institutions (PPZY2015B113).

\section{Supporting Information}

Supporting information for this article is available online at https://doi.org/10.1055/s-0037-1611676. 


\section{References and Notes}

(1) (a) Mabermann, C. E. Encyclopedia of Chemical Technology, Vol. 1; Wiley: New York, 1991. (b) Opsahl, R. Encyclopedia of Chemical Technology, Vol. 2; Wiley: New York, 1991. (c) Humphrey, J. M.; Chamberlin, A. R. Chem. Rev. 1997, 97, 2243. (d) Bray, B. L. Nat. Rev. Drug Discovery 2003, 2, 587. (e) Bode, J. W.; Fox, R. M.; Baucom, K. D. Angew. Chem. Int. Ed. 2006, 1248, 45. (f) Piontek, A.; Bisz, E.; Szostak, M. Angew. Chem. Int. Ed. 2018, 57, 11116.

(2) The Amide Linkage: Structural Significance in Chemistry, Biochemistry and Material Science; Wiley: New York, 2000.

(3) (a) Constable, D. J. C.; Dunn, P. J.; Hayler, J. D.; Humphrey, G. R.; Leazer, J. L. Jr; Linderman, R. J.; Lorenz, K.; Manley, J.; Pearlman, B. A.; Wells, A.; Zaks, A.; Zhang, T. Y. Green Chem. 2007, 9, 411. (b) Valeur, E.; Bradley, M. Chem. Soc. Rev. 2009, 38, 606. (c) Liu, J.; Liu, Q.; Yi, H.; Qin, C.; Bai, R.; Qi, X.; Lan, Y.; Lei, A. Angew. Chem. Int. Ed. 2014, 126, 502.

(4) Fujiwara, H.; Ogasawara, Y.; Yamaguchi, K.; Mizuno, N. Angew. Chem. Int. Ed. 2007, 46, 5202.

(5) Wu, X.-F.; Neumann, H.; Beller, M. Chem. Eur. J. 2010, 16, 9750.

(6) Kim, J. W.; Yamaguchi, K.; Mizuno, N. Angew. Chem. Int. Ed. 2008, 47, 9249.

(7) Yamaguchi, K.; Kobayashi, H.; Oishi, T.; Mizuno, N. Angew. Chem. Int. Ed. 2012, 51, 544.

(8) (a) Goto, A.; Endo, K.; Saito, S. Angew. Chem. Int. Ed. 2008, 47, 3607. (b) Ramón, R. S.; Marion, N.; Nolan, S. P. Chem. Eur. J. 2009, 15, 8695. (c) Hirano, T.; Uehara, K.; Kamata, K.; Mizuno, N. J. Am. Chem. Soc. 2012, 134, 6425.

(9) (a) Cao, L.; Ding, J.; Gao, M.; Wang, Z.; Li, J.; Wu, A. Org. Lett. 2009, 11, 3810. (b) Angeles, N. A.; Villavicencio, F.; Guadarrama, C.; Corona, D.; Cuevas-Yañez, E. J. Braz. Chem. Soc. 2010, 21, 905. (c) Rajendar, K.; Kant, R.; Narender, T. Adv. Synth. Catal. 2013, 355, 3591. (d) Sathyanarayana, P.; Upare, A.; Ravi, O.; Muktapuram, P. R.; Bathula, S. R. RSC Adv. 2016, 6, 22749.

(10) Song, Q.; Feng, Q.; Yang, K. Org. Lett. 2014, 16, 624.

(11) Chen, X.; Peng, Y.; Li, Y.; Wu, M.; Guo, H.; Wang, J.; Sun, S. RSC Adv. 2017, 7, 18588.

(12) Fan, W.; Yang, Y.; Lei, J.; Jiang, Q.; Zhou, W. J. Org. Chem. 2015, $80,8782$.

(13) (a) Tang, C.; Jiao, N. Angew. Chem. Int. Ed. 2014, 126, 6646. (b) Zhou, W.; Fan, W.; Jiang, Q.; Liang, Y.-F.; Jiao, N. Org. Lett. 2015, 17, 2542.
(14) Ma, H.; Zhou, X.; Zhan, Z.; Wei, D.; Shi, C.; Liu, X.; Huang, G. Org. Biomol. Chem. 2017, 15, 7365.

(15) (a) Fang, Z.; Feng, Y.; Dong, H.; Li, D.; Tang, T. Chem. Commun. 2016, 11120. (b) Fang, Z;; Wei, C.; Lin, J.; Liu, Z.; Wang, W.; Xu, C.; Wang, X.; Wang, Y. Org. Biomol. Chem. 2017, 15, 9974. (c) Wang, Y.; Wei, C.; Tang, R.; Zhan, H.; Lin, J.; Liu, Z.; Tao, W.; Fang, Z. Org. Biomol. Chem. 2018, 16, 6191.

(16) Zhang, L.; Bi, X.; Guan, X.; Li, X.; Liu, Q.; Barry, B.-D.; Liao, P. Angew. Chem. Int. Ed. 2013, 52, 11303.

(17) (a) Huang, L.; Cheng, K.; Yao, B.; Xie, Y.; Zhang, Y. J. Org. Chem. 2011, 76, 5732. (b) Zhang, C.; Feng, P.; Jiao, N. J. Am. Chem. Soc. 2013, 40, 15257. (c) Chen, X.; Chen, T.; Ji, F.; Zhou, Y.; Yin, S.-F. Catal. Sci. Technol. 2015, 5, 2197. (d) Bisz, E.; Szostak, M. ChemSusChem 2017, 10, 3964.

(18) (a) Li, H.; He, Z.; Guo, X.; Li, W.; Zhao, X.; Li, Z. Org. Lett. 2009, 11, 4176. (b) Liu, J.; Ma, S. Org. Lett. 2013, 15, 5150. (c) Ratnikov, M. O.; Xu, X.; Doyle, M. P. J. Am. Chem. Soc. 2013, 135, 9475. (d) Shen, T.; Yuan, Y.; Song, S.; Jiao, N. Chem. Commun. 2014, 4115. (e) Chen, X.; Chen, T.; Ji, F.; Zhou, Y.; Yin, S.-F. Catal. Sci. Technol. 2015, 5, 2197. (f) Wang, L.; Shang, S.; Li, G.; Ren, L.; Lv, Y.; Gao, S. J. Org. Chem. 2016, 81, 2189. (g) Xing, Q.; Lv, H.; Xia, C.; Li, F. Chem. Commun. 2016, 489.

(19) (a) Palomo, C.; Aizpurua, J. M.; Cuevas, C.; Urchegui, R.; Linden, A. J. Org. Chem. 1996, 61, 4400. (b) Fung, H. S.; Li, B. Z.; Chan, K. S. Organometallics 2012, 31, 570.

(20) Typical synthetic procedure: To a mixture of 1a (60 mg, 0.4 mmol) and $\mathrm{NaN}_{3}(78 \mathrm{mg}, 1.2 \mathrm{mmol})$ in DMF $(2.0 \mathrm{~mL})$ were added $\mathrm{Fe}_{2}\left(\mathrm{SO}_{4}\right)_{3}(16.0 \mathrm{mg}, 0.04 \mathrm{mmol})$, TEMPO (12.5 mg, 0.08 $\mathrm{mol})$ and $\mathrm{H}_{2} \mathrm{O}(0.216 \mathrm{~mL}, 12 \mathrm{mmol})$. The reaction mixture was heated to $120^{\circ} \mathrm{C}$ and stirred for $30 \mathrm{~h}$ under an oxygen atmosphere, until the substrate 1a was consumed as indicated by TLC. The solvent was removed under reduced pressure and the residue was purified by flash column chromatography (eluent: petroleum ether/ethyl acetate $=2: 1)$ to afford product $\mathbf{2 a}(57.4$ mg, $95 \%$ yield). ${ }^{1} \mathrm{H}$ NMR $\left(500 \mathrm{MHz}, \mathrm{CDCl}_{3}\right): \delta=7.79(\mathrm{~d}, J=8.5 \mathrm{~Hz}$, $2 \mathrm{H}), 6.94(\mathrm{~d}, J=8.5 \mathrm{~Hz}, 2 \mathrm{H}), 5.96(\mathrm{~s}, 1 \mathrm{H}), 5.74(\mathrm{~s}, 1 \mathrm{H}), 3.86(\mathrm{~s}$, $3 \mathrm{H}) .{ }^{13} \mathrm{C}$ NMR $\left(125 \mathrm{MHz}, \mathrm{CDCl}_{3}\right): \delta=168.8,162.5,129.2,125.5$, 113.7, 55.4. HRMS (ESI): $\mathrm{m} / z[\mathrm{M}+\mathrm{H}]^{+}$calcd. for $\mathrm{C}_{8} \mathrm{H}_{10} \mathrm{NO}_{2}$ : 152.0712; found: 152.0714 . 